\title{
Las técnicas de reproducción asistida y sus efectos en la conceptualización legal de la maternidad, paternidad y filiación
}

\author{
Joaquina Gabriela Ruiz Burgos \\ Alumna Maestría en Derecho, Universidad de Guadalajara. México \\ gabyrb7389@gmail.com \\ Rubén Jaime Flores Medina \\ Doctor en Derecho por la Universidad de Guadalajara. México \\ floresmedinar@hotmail.com
}

Recibido: 18/11/2017

Dictaminado: 26/02/2018

\section{Resumen}

En la actualidad las técnicas de reproducción asistida forman parte de la realidad social, por lo que resulta primordial que México comience a regular las diversas situaciones jurídicas que estas conllevan.

Palabras clave: Técnicas de reproducción asistida, bancos de semen, infertilidad, ética, Presunción de Filiación

\section{Assisted reproduction techniques and their effects on the legal conceptualization of motherhood, paternity and filiation}

\footnotetext{
Abstract

Currently assisted reproduction techniques are part of the social reality, so it is essential that Mexico begins to regulate the various legal situations that these entails.

Key words: Assisted reproduction techniques, semen banks, infertility, ethics, presumption of filiation.
} 


\section{Sumario}

I. Introducción; II. Bancos de semen, regulación e incidencia legal; III. Teorías respecto la ética de la práctica de las "TRA"; IV. Alteraciones en las concepciones legales de la maternidad, paternidad y filiación; V. Legislación respecto la filiación derivada de Técnicas de Reproducción Asistida: a) México. b) España. c) Argentina; VI. La determinación de la filiación; VII. La filiación desde la perspectiva del hijo; VIII. Posibles implicaciones prácticas en la materia notarial; IX. Conclusiones; Bibliografía

"Infans conceptur pro nato habetur quotis de commodis ejur agitur"

$<$ Máxima romana sobre el nasciturus $>$.

\section{Introducción}

En este trabajo se estudian las implicaciones legales de la aplicación de las técnicas de reproducción asistida -especialmente la de inseminación artificial- en el ámbito de las regulaciones actuales sobre filiación y paternidad.

Si entendemos que la filiación es una institución de naturaleza civil que nos explica:

"La liga o relación de los hijos con su madre o padre, con efectos jurídicos...Parentesco consanguíneo en primer grado" (Martínez: 2007, pág. 75-129).

Entonces, el tema de la reproducción asistida por medios artificiales, nos obliga a repasar los efectos que el nacimiento, resulta para el recién nacido y los actores de este drama bioético.

Se considera que las técnicas de reproducción asistida son una suplencia al defecto biológico o natural, sin embargo en la actualidad procrear un hijo no es solo un proceso natural, es un proceso social y jurídico, es una decisión que se toma por los participantes, pretendiendo ser conscientes de las consecuencias que conlleva su actuación en todos los ámbitos: moral, económico, social y jurídico.

"En todas las sociedades humanas la procreación es un fenómeno complejo en el que se 
entrelazan procesos biológicos y sociales. Tener un hijo nunca se define como un mero hecho de la naturaleza, sino que es un acto social fundamental que cambia el estatus de los progenitores y por el que se reconstituyen sus vínculos". (J. Bestard: 2003, pag. 136)

El desarrollo del presente trabajo -desde nuestro particular punto de vista-, resulta un reto; toda vez que en México no tienen ningún avance legislativo sobre el tema. Por lo que, abordar esta cuestión precariamente tratada desde la academia, nos obliga a repasar puntualmente todas las diversas aristas que la legislación y la práctica social nos ofrece. Sobre todo, si se abordan las diferentes técnicas de reproducción asistida, desde la llamada "identidad de género".

Hay que resaltar el hecho de que abordar estos temas requiere de estudios multidisciplinarios, que abarcan ramas de la medicina; de la sociología; del Derecho; de la antropología; de la historia y de varias disciplinas de la ciencia social.

Con la difusión de este trabajo, pretendemos aportar una inquietud académica al precario esfuerzo legislativo, sobre una interesante cuestión que debe ser explorada para una mejor comprensión de las relaciones afectivas, familiares y sus efectos e implicaciones en el ámbito de lo social.

Se comprende -desde luego-, que una tarea sobre la regulación de las técnicas de reproducción asistida pudiese rebasar por mucho la labor de la academia. Pero cualquier intento de regularizar las situaciones problemáticas que de hecho existen- sobre filiación, maternidad y paternidad, ya representa de cualquier modo, un avance en la cuestión.

\section{Bancos de Semen, regulación e incidencia legal}

La reproducción humana es un fenómeno natural que se ha visto re-conceptualizado por la incorporación de las llamadas Técnicas de Reproducción Asistida, que denominaremos para efectos de este trabajo como "TRA". Dichas técnicas tienen por objeto la procreación, en los casos que no se pueden lograr de forma natural.

Estas técnicas pueden ser definidas como: "el conjunto de tratamientos médicos y procedimientos diversos que facilitan el embarazo cuando éste no se consigue de forma natural; ya sea por infertilidad masculina, femenina o ambas" 
Los denominados "Bancos de Semen", son los repositorios biológicos más utilizados en la actualidad, como una herramienta de la técnica de reproducción asistida.

Una Técnica de Reproducción Asistida, que viene supliendo al fenómeno natural de la procreación, lo constituye el procedimiento usual de introducir el material genético masculino previamente sustraído del repositorio -y que se elige para cada caso concreto-, dentro del útero de la mujer, controlando de esta manera la ovulación de ésta, para aumentar su probabilidad de embarazo.

Autores han opinado que se acude a la inseminación artificial cuando nos encontramos que: "los factores que hacen imposible la deposición (depositar) en la vagina del líquido seminal o la subida de los espermatozoides por las vías genitales femeninas internas" (Lino Ciccone: 2006, pag. 214).

Alguna de las particularidades que este autor nos explica son; que el líquido seminal los proporciona el "Banco de semen". Líquido que es obtenido de donadores de semen. El esperma se conserva a temperaturas muy bajas. Hay que advertir la disminución de probabilidades del embarazo por este medio, frente a las altas posibilidades cuando se deposita el "semen fresco" de una cópula; ya que la movilidad del espermatozoide implantado baja hasta un 35\% con relación a éste último.

De acuerdo a este autor mencionado, desde 1953 la inseminación artificial se utiliza en la zootécnica, pero tan sólo hace 30 años en el ámbito de los seres humanos.

“Los tratamientos de infertilidad tienen por objeto proporcionar un hijo biológico a los pacientes". (S. Turner Saelzer: 2000, pag. 13 - 26)

Actualmente los Bancos de Semen se dividen en 3 campos:

- Aquellos con la tarea de conservación en frío del producto de donadores para la inseminación artificial heteróloga. (el donante es un tercero)

- Aquellos con la tarea de conservación en frío de semen masculino de baja fertilidad para la inseminación artificial homóloga. (el donante es la pareja)

- Aquellos con la tarea de conservación en frío del semen de pacientes que 
enfrentan una lesión permanente de espermatogénesis o que se someten a vasectomía y pretenden reservarlos para un futuro.

Ejemplos de usos para los fines del punto anterior, lo encontramos: 1. En la congelación pre-vasectomía; 2. Cuando existen Tumores testiculares en el paciente; 3. Cuando éstos pacientes oncológicos son sometidos a quimioterapia o radioterapia; 4. Con pacientes cuya baja calidad seminal o cantidad seminal empeore con el tiempo; 5. En situaciones en las que el varón vaya a someterse a un ambiente tóxico que pueda perjudicar su calidad seminal.

De acuerdo a la Comisión Federal para la Protección contra Riesgos Sanitarios (COFEPRIS), en México existen a la fecha 52 centros autorizados para realizar técnicas de reproducción asistida.

\section{Teorias respecto a la ética de la práctica de las "TRA"}

La Bioética es una disciplina propuesta desde el año de 1971, y fue definida como "la disciplina que combina el conocimiento biológico con el de los valores humanos".

En la actualidad se han desarrollado diversas teorías de bioética respecto a las técnicas de reproducción asistida, en el presente trabajo analizamos principalmente dos:
A. El acto del amor conyugal es el único lugar digno de la procreación humana. Explica el autor anteriormente mencionado Lino Ciccone, que partiendo de la premisa de que el acto de amor conyugal es el único lugar digno de la procreación humana; entonces cualquier intervención en el proceso que excluya el acto conyugal, es éticamente inadmisible, e indigno de la procreación. Sin embargo, es lícito moralmente cuando es tan solo una ayuda para el referido acto de procreación.
Esta teoría rechaza las técnicas de asistencia conyugal, cuando el producto, o el objetivo no son alcanzados a través del acto conyugal.

Por ejemplo, en los siguientes casos: 
- Inseminación artificial homóloga; cuando el material genético es recogido del mismo acto conyugal. Se considera plenamente dentro de la licitud moral.

- Inseminación homóloga; cuando el material es recogido a través o mediante una masturbación. Se considera como ilícito, moralmente hablando.

- Inseminación heteróloga; cuando un tercero es el donante del material genético. Es gravemente considerado como un ilícito moral.

B. En la actualidad, la descendencia genética es un patrimonio cultural. Por otro lado, el autor Giovanni Berlinguer explica que en la actualidad, el deseo de la maternidad y la paternidad fundadas en la gestación materna y en la descendencia genética, es un legítimo patrimonio cultural de nuestra época. Es una libre elección. Es decir; actualmente gracias a los avances de la ciencia, el poder procrear con nuestra genética es una decisión que nos pertenece y que podemos tomar. Es un derecho, toda vez que el acceso a la reproducción asistida implica el ejercicio de una serie de derechos humanos, entre ellos: el derecho a fundar una familia, a la igualdad, a la no discriminación, a la autonomía reproductiva, a la salud y a beneficiarse del progreso científico.

\section{Alteraciones en las concepciones legales de la maternidad, paternidad y filiación}

El concepto de familia, proveniente del derecho romano. Su etimología la enmarca en los siguientes términos: "famulus" que significa 'sirviente'. Que deriva a su vez de "famel", 'esclavo'.

En el sentido primitivo familia aludía al conjunto de esclavos y sirvientes que se hallaban bajo la autoridad del "Pater familias".

Según el Derecho Romano, el término familia tenía dos sentidos:

a) En sentido propio se entendía por familia o domus “... a la reunión de 
personas colocadas bajo la autoridad o la manus de un jefe único..." En latín: “...jure propio familiam dicimus plures personas quae sunt sub unius potestate aunt natura jure subjectae..."'. Era un régimen patriarcal, entonces. La familia comprende bajo este enfoque a los descendientes que están sometidos a la autoridad del paterfamilias, incluyendo a su mujer in manu que está en una condición análoga a la de una hija (loco filiae).

b) En un segundo sentido, familia resultaba de un vínculo, ligadura o unión civil entre los miembros de dicha familia por agnatio. Dado su entroncamiento natural de padres a hijos.

Asemejándose al primer sentido de vínculo jurídico que hemos descrito del Derecho Romano, se ubican las familias modernas, dentro de las cuales eran considerados dentro de la familia otros individuos ajenos a la sangre del paterfamilias; como sus esclavos, o aquellas personas sujetas a la potestad del jefe, quien ejercía la manus. (Petit: 2017, pag. 95 - 99)

Este antiguo concepto basado en el matrimonio, la heterosexualidad, la procreación natural en donde la progenitora era considerada la madre y el marido el padre; ha evolucionado. Creando en la sociedad nuevos modelos de familia formados por parejas homosexuales, heterosexuales, monoparentales, en las cuales se ponen en cuestión la concepción de la maternidad y la paternidad tradicional, que era solamente la biológica. (Muñoz: 2016, pag. 24 - 36)

“...La filiación es la relación entre unos padres y sus hijos; $y$ debe determinarse formalmente para generar efectos jurídicos...” (Muñoz: 2016. pag. 24 - 36)

Ahora la finalidad de las uniones entre personas del mismo sexo, ya no están basadas en la reproducción, como en Roma, que las fundaban jurídicamente en la procreación. Y consecuentemente los matrimonios que resultan de esta uniones ya no persiguen necesariamente esta finalidad. ${ }^{2}$

1 Petit Eugéne, "Tratado elemental de Derecho Romano", 23 Edición, Ed. Porrúa, México, 2007. Pp. 95-99 2 En ese sentido consultar la tesis aislada(Constitucional) 161265; PXXII/2011 del Pleno, bajo el Tomo XXXIV, de Agosto del 2011, página 879, de la Novena época con el rubro: "MATRIMONIO. LA "POTENCIALIDAD" DE LA REPRODUCCIÓN NO ES UNA FINALIDAD ESENCIAL DE AQUELLA INSTITUCIÓN”. 
La autora Lucia Muñoz Benito (2016), nos explica que el vínculo de filiación crea una serie de efectos como lo son: la determinación de los apellidos, la obligación de los padres de proveer el adecuado desarrollo de los menores; así como, la de proporcionar alimentos, y los consecuentes derechos sucesorios, y a una nacionalidad.

Actualmente, en la sociedad existen varios tipos de paternidad: a.- Padres biológicos: son los que aportan el material biológico para concepción del niño; b.- Padres de crianza: quienes adoptan el papel de educación del niño; c.- Padres legales: son los que la ley reconoce, normalmente quien ejerce la patria potestad, por lo tanto, quien debe cumplir con las obligaciones hacia el niño; d.- Padres adoptivos: son reconocidos por la ley; es decir son padre legalmente, pero no biológicamente. Son quienes ejercen la patria potestad sobre el adoptado.

Con respecto a quien emite la voluntad de determinar quien sea el padre; en la "TRA", se sustituye el factor biológico ("determinante" desde luego por la fuerza que impone la naturaleza), con el volitivo; eligiendo la fuente del material genético "determinado" por el usuario.

Como resultado de dicho fenómeno, apoyado con las técnicas de reproducción asistida, encontramos entonces los siguientes efectos jurídicos en cuanto a filiación, maternidad y paternidad:

- Co-maternidad: La patria potestad es ejercida por dos madres;

- Co-paternidad: La patria potestad es ejercida por dos padres;

- Hijos de parejas del mismo sexo por medio de adopción; Donde ninguno de ellos es el padre o madre natural;

- Hijos de parejas del mismo sexo por medio de reproducción asistida. Donde uno de ellos es el padre o madre natural;

\section{Legislación respecto la filiación derivada de técnicas de reproducción asistida}

Para que se cumplan las garantías de certeza y seguridad jurídica para todas las actividades que venimos reseñando, es menester abordar el tema de legislación. $\mathrm{Y}$ en particular de los estudios sobre legislación comparada sobre el tema. De 
esta manera, nos darán luz acerca de las "TRA", el marco normativo vigente en Argentina, España y México. De nuestro país la reglamentación secundaria aplicable.

\section{a) México}

Lamentablemente en México, no existe legislación específica respecto la filiación en los casos de reproducción asistida, ni en los casos de adopción por parejas del mismo sexo, aunque ya se encuentren iniciativas de ley presentadas en el Congreso de la Unión en este año de 2017, como es el caso de la . Pero hay que advertir que sí se prevén regulaciones para que se apoye actualmente la práctica de dichas técnicas en nuestro país; pues nos referimos a los fundamentos del Artículo $1^{\circ}$ Constitucional, que establece a los derechos humanos como reconocidos por la propia Constitución Política de los Estados Unidos Mexicanos, las garantías otorgadas para su ejercicio, y los tratados internacionales sobre la materia que pueden ser aplicables en nuestro país sobre esa materia.

“Artículo 1o. En los Estados Unidos Mexicanos todas las personas gozarán de los derechos humanos reconocidos en esta Constitución y en los tratados internacionales de los que el Estado Mexicano sea parte, asi como de las garantías para su protección, cuyo ejercicio no podrá restringirse ni suspenderse, salvo en los casos y bajo las condiciones que esta Constitución establece...."

Además, en el artículo $4^{\circ}$ Constitucional, se establece que “...todas las personas tienen el derecho a decidir de manera libre, responsable e informada el número de hijos que desean tener y el espaciamiento entre ellos...".

En la Ley General de Salud, tan sólo encontramos el artículo 68 en el que se menciona el tema; mismo que a la letra dice:

“Artículo 68.- Los servicios de planificación familiar comprenden:

$I V$. El apoyo y fomento de la investigación en materia de anticoncepción, infertilidad humana, planificación familiar y biología de la reproducción humana;"” 
México ha suscrito la Convención Americana sobre Derechos Humanos (Pacto de San José); la cual en su artículo $17^{\circ}$ establece la protección a la familia y su derecho a fundar una familia. De cumplimiento obligatorio para nuestro país derivado de su vigencia actual.

En el Código Civil del estado de Jalisco, en el Título Sexto: De la Paternidad y Filiación; se nos explica que se presumen hijos de matrimonio, los hijos nacidos dentro del matrimonio. Estableciendo los supuestos de que sean nacidos después de ciento ochenta días contados desde la celebración del matrimonio; o de que sean nacidos dentro de los trescientos días siguientes a la disolución del matrimonio, por cualquier causa que se origine ésta.

En los supuestos anteriores, siempre y cuando no se hubiere practicado el examen de gravidez en la mujer, ya que de resultar negativo no se imputará al ex cónyuge la paternidad.

Por otra parte, el siguiente artículo establece:

"Artículo 457.- Contra esta presunción no se admite otra prueba que la de haber sido fisicamente imposible al marido tener acceso carnal con su mujer, en los primeros ciento veinte días de los trescientos que han precedido al nacimiento o en el caso de fecundación asistida con semen del marido."

En el Distrito Federal (Ciudad de México) y Guerrero se han presentado iniciativas legislativas; mientras que en el estado de Puebla ya se preparó una iniciativa pero todavía no se presenta al congreso local.

En Tabasco, el artículo $92^{\circ}$ del Código Civil regula la gestación subrogada como un supuesto de filiación y determina qué debe entenderse por madre gestante sustituta y madre subrogada.

En el estado de Guerrero se presentó el 8 de septiembre de 2011 una iniciativa de Ley de Maternidad Subrogada. ${ }^{3}$

Por último, en legislación comparada diremos que el artículo 92 del Código Civil del estado de Tabasco, es muy específico respecto del tema que estamos

3 http://informe.gire.org.mx/caps/cap6.pdf 
abordando, y que a la letra dice:

“ARTICULO 92.

En los casos en los que participe una madre subrogada, deberá estarse a lo ordenado para la adopción plena. Se entiende por madre gestante sustituta, la mujer que lleva el embarazo a término y proporciona el componente para la gestación, más no el componente genético. Por el contrario, la madre subrogada provee ambos: el material genético y el gestante para la reproducción. Se considera madre contratante a la mujer que convenga en utilizar los servicios de la madre gestante sustituta o de la madre subrogada, según sea el caso.

Salvo el caso de que se trate de un hijo nacido de una madre gestante sustituta, cuando el hijo nazca de una mujer casada que viva con su esposo, el Oficial del Registro Civil no podrá asentar como padre a otro que no sea el mismo marido, excepto que éste haya desconocido al hijo y exista sentencia ejecutoria que así lo declare. “

\section{b) España}

En España desde 1988 creó una ley especial que regula las técnicas de reproducción asistida, actualmente se rigen por la Ley 14/2006, de 26 de mayo, sobre técnicas de reproducción humana asistida; misma legislación que regula que puedan ser usuarias de las "TRA", aquellas mujeres mayores de 18 años; y si la mujer es casada, necesitará el consentimiento por escrito del esposo.

Es importante señalar que sólo prevén el otorgamiento del consentimiento, para los casos de matrimonio entre parejas heterosexuales; aunque su legislación permite los matrimonios de personas del mismo sexo desde el año 2005; normativa que también les concedió el derecho de adoptar.

Podría parecer que fue una omisión involuntaria del legislador, el no prever la emisión del consentimiento de la pareja para los casos de unión entre personas del mismo sexo; ya que en los artículos subsecuentes, se supera esta omisión al regular los casos de matrimonios entre dos mujeres. En cuyo caso, se permite que la cónyuge que no se sometió a la técnica de reproducción asistida, pueda reconocer al hijo antes de su nacimiento, acudiendo ante el Encargado del 


\section{Registro Civil.}

Pero hay que advertir que se le concede como un derecho; mas no como una obligación, en el caso del marido que consintió la "TRA", como se estipula en el artículo $8^{\circ}$ de dicha ley.

De acuerdo a la autora Ana Díaz (2007), lo anterior responde a lo estipulado por el Código Civil Español en su artículo $116^{\circ}$ que establece la presunción de filiación de los hijos nacidos dentro del matrimonio; por lo que señala que esta diferencia que hace el legislador...:

“...genera una posición jurídica diferente para el cónyuge de la mujer que se somete a un tratamiento de reproducción asistida, según su sexo, sino también para la propia usuaria de éste, cuyo ámbito de autonomía personal en el ejercicio de su libertad reproductiva es más o menos amplio según esté casada con otra mujer o con un varón..., ”. (Díaz, 2007)

Por su parte para Muñoz (2016), la concepción de Paternidad cambia; toda vez que tradicionalmente estaba basada con la verdad biológica, sin embargo con las "TRA", esto ya no es la base de la filiación, sino del deseo de ser el padre.

Es importante señalar que para este autor, el donante de ninguna manera podrá reconocer la filiación; sólo se considera como un donante: no como un padre. Además, establece las condiciones para la filiación post mortem.

Para una mayor claridad transcribimos los artículos relativos a la ley vigente en España respecto a las técnicas de Reproducción Asistida:

“Artículo 6. Usuarios de las técnicas. 1. Toda mujer mayor de 18 años y con plena capacidad de obrar podrá ser receptora o usuaria de las técnicas reguladas en esta Ley, siempre que haya prestado su consentimiento escrito a su utilización de manera libre, consciente y expresa. La mujer podrá ser usuaria o receptora de las técnicas reguladas en esta Ley con independencia de su estado civil y orientación sexual. 3. Si la mujer estuviera casada, se precisará, además, el consentimiento de su marido, a menos que estuvieran separados legalmente o de hecho y asi conste de manera fehaciente. El consentimiento del cónyuge, prestado antes de la utilización de las técnicas, deberá reunir idénticos requisitos de expresión libre, consciente y formal."

“Artículo 7 Filiación de los hijos nacidos mediante técnicas de reproducción asistida. 3. Cuando la mujer estuviere casada, y no separada legalmente o de hecho, con otra mujer, esta última podrá manifestar conforme a lo dispuesto en la Ley del Registro Civil que consiente en que se determine a su favor la filiación respecto al hijo nacido de su cónyuge." 
“Artículo 8 Determinación legal de la filiación. 1. Ni la mujer progenitora ni el marido, cuando hayan prestado su consentimiento formal, previo y expreso a determinada fecundación con contribución de donante o donantes, podrán impugnar la filiación matrimonial del hijo nacido como consecuencia de tal fecundación. 3. La revelación de la identidad del donante en los supuestos en que proceda conforme al artículo. 5.5 de esta Ley no implica en ningún caso determinación legal de la filiación."

“Artículo 9 Premoriencia del marido. 1. No podrá determinarse legalmente la filiación ni reconocerse efecto o relación jurídica alguna entre el hijo nacido por la aplicación de las técnicas reguladas en esta Ley y el marido fallecido cuando el material reproductor de éste no se halle en el útero de la mujer en la fecha de la muerte del varón. 2. No obstante lo dispuesto en el apartado anterior, el marido podrá prestar su consentimiento, en el documento a que se hace referencia en el artículo 6.3, en escritura pública, en testamento o documento de instrucciones previas, para que su material reproductor pueda ser utilizado en los 12 meses siguientes a su fallecimiento para fecundar a su mujer. Tal generación producirá los efectos legales que se derivan de la filiación matrimonial. El consentimiento para la aplicación de las técnicas en dichas circunstancias podrá ser revocado en cualquier momento anterior a la realización de aquéllas. Se presume otorgado el consentimiento a que se refiere el párrafo anterior cuando el cónyuge supérstite hubiera estado sometido a un proceso de reproducción asistida ya iniciado para la transferencia de pre-embriones ${ }^{4}$ constituidos con anterioridad al fallecimiento del marido. 3. El varón no unido por vínculo matrimonial podrá hacer uso de la posibilidad prevista en el apartado anterior; dicho consentimiento servirá como título para iniciar el expediente del apartado 8 del artículo 44 de la Ley 20/2011, de 21 de julio, del Registro Civil, sin perjuicio de la acción judicial de reclamación de paternidad."

“Artículo 10 Gestación por sustitución. 1. Será nulo de pleno derecho el contrato por el que se convenga la gestación, con o sin precio, a cargo de una mujer que renuncia a la filiación materna a favor del contratante o de un tercero. 2. La filiación de los hijos nacidos por gestación de sustitución será determinada por el parto. 3. Queda a salvo la posible acción de reclamación de la paternidad respecto del padre biológico, conforme a las reglas generales."

\section{c) Argentina}

\section{En Argentina, en el año 2013 se promulgó la Ley Nacional de Fertilización Humana Asistida, identificada como: $\mathrm{N}^{0}$ 26.862, de la cual analizamos los artículos relativos la filiación.}

\footnotetext{
4 Por cierto, el tema del concepto de pre-embrión resulta un término artificioso y sin sustento científico, ya que se trata de un completo embrión que No ha sido anidado en el útero de madre alguna, o fecundado no hayan transcurrido más de 14 días desde su fecundación. Por lo que consideramos que su utilización sin otros fines, más que su desechamiento o destrucción, atenta contra la vida humana. Pero este tema es materia de futuras investigaciones.
} 
Advertimos una regulación similar a la de España, por lo que reconoce como padres legales a la mujer que se sometió a dicho tratamiento y del cónyuge que haya otorgado su consentimiento en el caso. En efecto, observamos las regulaciones siguientes:

"Título IV: De la Filiación Capitulo I: Principios Generales. Artículo 18: Las personas nacidas mediante el uso de Técnicas de Reproducción Humana Asistida son hijos de la mujer que los diera a luz y del hombre o de la mujer que ha prestado su consentimiento previo, informado y libre, independientemente de que los gametos hayan sido aportados por terceros, debiendo hacer constar dicha circunstancia en el Registro del Estado Civil y Capacidad de las Personas..."

Observamos que en cuanto a los donantes, anula cualquier tipo de vínculo jurídico. Sin embargo, podemos decir que es previsora, estableciendo que aunque no existe un vínculo de filiación, será impedimento para contraer un futuro matrimonio.

Artículo 19: Las personas nacidas mediante Técnicas de Reproducción Humana Asistida con la utilización de gametos aportados por terceros, en ningún caso podrán reclamar a los aportantes derechos vinculados a la filiación, no generándose vínculo jurídico alguno entre ellos, excepto a los fines de los impedimentos matrimoniales en los mismos términos que la adopción plena. Los aportantes de gametos para terceros en ningún caso podrán reclamar derechos vinculados a la filiación respecto de los nacidos mediante Técnicas de Reproducción Humana Asistida con la utilización de gametos aportados por ellos.

Se mantiene el secreto de quien fue el donante. Este artículo contraviene las convenciones internacionales en las que se estipula que toda persona tiene derecho a conocer de donde proviene, hecho o situación que más adelante estudiamos.

Artículo 20: La información relativa a que la persona ha nacido por el uso de Técnicas de Reproducción Humana Asistida con gametos aportados por un tercero, debe constar en el correspondiente legajo base para la inscripción del nacimiento. En ningún caso podrá revelarse la identidad del aportante.

Al igual que en la ley española, se establecen las condiciones para la filiación post mortem.

“Capítulo II: Presunción de Filiación. Artículo 21: Cuando se produzca la muerte del o 
la cónyuge, o conviviente, o pareja de la mujer que da a luz, no existe vínculo filial entre los nacidos mediante el uso de Técnicas de Reproducción Humana Asistida y la persona fallecida, si el procedimiento para la consecución del embarazo no fue iniciado antes de que ocurra la muerte. Exceptúese de lo dispuesto en el párrafo anterior cuando: a. La persona fallecida ha otorgado su consentimiento previo, informado y libre protocolizado ante escribano público; o mediante testamento ha declarado de modo expreso que se dé inicio al procedimiento de fertilización por Técnicas de Reproducción Humana Asistida mediante la utilización de sus gametos después del fallecimiento. b. El inicio del procedimiento mediante Técnicas de Reproducción Humana Asistida, con resultados exitosos, se produce dentro del año siguiente al deceso."

Artículo 22: Salvo prueba en contrario, se presumen hijos del o la cónyuge los nacidos mediante el uso de Técnicas de Reproducción Humana Asistida después de la celebración del matrimonio y hasta los trescientos (300) días posteriores a la interposición de la demanda de divorcio o nulidad del matrimonio, de la separación de hecho, de la muerte o presunción de fallecimiento, siempre que él o la cónyuge hubiere prestado su consentimiento previo, informado y libre..."

Además, existen otros pocos países con legislación en la materia:

-Austria, donde ya se practica la inseminación artificial desde los años de 19881990. Y exige "Escritura Notarial" donde conste el consentimiento formal ante un Notario, realizado en el caso de parejas de "hecho" que utilicen esperma de terceros. $^{5}$

-Suecia, la Ley sobre la Inseminación Artificial (1984) y Ley sobre la Fecundación in Vitro. (1988)

-Dinamarca, la Ley sobre el Establecimiento de un Consejo Ético y la Regulación de Algunos Experimentos Biomédicos (1987).

-Noruega, la Ley sobre Fertilización Artificial (1987) y Ley sobre las Aplicaciones Biotecnológicas en Medicina (1994).

-Alemania, la Ley sobre Protección del Embrión Humano (1990).

-Inglaterra, la Ley sobre Fertilización Humana y Embriología (1991).

-Costa Rica, se adoptan medidas al respecto desde 1993.

5 https://www.youtube.com/watch?v=4IjpI3LnoyU. (consultado el 5 de noviembre a las $17.00 \mathrm{hrs}$ ) 


\section{La determinación de la filiación}

El factor más importante para la determinación de la filiación será, en primer lugar, si se deriva de un vínculo matrimonial. Después, si se produjo una "TRA" homóloga o heteróloga.

\section{Filiación como consecuencia de las "TRA" homóloga, dentro del matrimonio}

El caso más sencillo será cuando se recurre al "TRA" dentro del matrimonio y se realiza homogéneamente; es decir, con el material genético del esposo, en los cuales coincidirán los padres biológicos con los padres jurídicos.

Explica la autora Muñoz (2016) antes mencionada, que:

"Lo anterior es sencillo, ya que además de lo explicado, se atenderá al principio romano= mater semper certa est... La madre siempre es cierta."

Es decir, la maternidad vendrá determinada por el parto. Y esta determinación de maternidad, será obtenida a través de la presunción de que son nacidos dentro del matrimonio.

\section{Filiación como consecuencia de las "TRA" homóloga post mortem, dentro del matrimonio}

En este caso, cada legislación establecerá sus criterios. Sin embargo, de manera general; el hijo concebido con el material genético del esposo fallecido, siempre que éste haya otorgado su consentimiento mediante la forma prescrita por las diversas legislaciones, será considerado como hijo del matrimonio.

\section{Filiación como consecuencia de las "TRA" heteróloga, dentro del matrimonio}

En estos casos, el donante no tiene ningún vínculo jurídico. Y el hijo nacido, se considera hijo del matrimonio donado. En estos casos se pueden dar 2 situaciones: En Matrimonios heterosexuales; y en Matrimonios homosexuales. 
En el caso de los matrimonios heterosexuales en que ocurre este evento, es necesario el consentimiento del marido para que le sea reconocida la paternidad. Así, se presume como hijo nacido dentro del matrimonio. (Muñoz, 2016). Los vicios en la expresión del consentimiento podrían dar lugar a la impugnación de dicha filiación. En el caso de los matrimonios homosexuales, cuando se produce la inseminación artificial, ésta ocurre en uniones homosexuales entre mujeres. Ahora llamado en España como: "doble maternidad por naturaleza". (Muñoz, 2016). Debido a que solo existen 2 tipos de filiación: La natural y la adoptiva. Al no darse por la vía adoptiva, tendría que ser natural. Dejando un vacío regulatorio.

Al respecto la mencionada Lucía Muñoz (2016), propone un tercer tipo de filiación:

\section{La derivada de la Técnicas de Reproducción Asistida "TRA"}

Dentro de diversas legislaciones, como en el caso de España, se prevé que la que es cónyuge o pareja de quien fue sujeta a las "TRA", deberá aceptar ante el encargado de la Oficina del Registro Civil su consentimiento, antes del nacimiento del niño y previo matrimonio.

\section{Filiación como consecuencia de las "TRA" homóloga, fuera del matrimonio}

Esta situación se advierte cuando una pareja, presuntamente estable, desea procrear un hijo, por lo que acuden a la aplicación de las "TRA" y se utiliza el material genético de la pareja. La filiación, en estos casos se determinará por la manifestación del consentimiento y su declaración de voluntad. Coincidirán los padres biológicos y los jurídicos, tan sólo no existe el vínculo matrimonial.

\section{Filiación como consecuencia de las "TRA" homóloga post mortem, fuera del matrimonio}

También se pueden advertir algunos casos como el de este apartado, en los cuales quienes aplican la ley tendrán que ubicar la normativa vigente para resolver 
el tema de filiación. Filiación como consecuencia de las "TRA" heterologa, fuera del matrimonio. Podemos encontrar casos de "TRA" heteróloga fuera del matrimonio bajo dos supuestos distintos: Uno. En el caso de una pareja estable donde encontramos el consentimiento manifiesto de quien quiere ser el Padre, para que se reconozca dicha paternidad; y Dos en el caso de la mujer soltera que la Ley establece que el donante nunca podrá tener ningún tipo de vínculo jurídico con ella y con el producto.

\section{La filiación desde la perspectiva del hijo}

\section{EI derecho a conocer el propio origen}

Este debate surgió con la institución de la Adopción. Ahora es aplicable también a las "TRA". De acuerdo en lo que señalan los coautores de la obra: "Técnicas de Reproducción Humana Asistida. Una perspectiva desde los intereses del hijo."(S. Turner Saelzer, 2000), esta necesidad de determinar a los sujetos de raza Aria, surgió en Alemania y adelanta la aparición de procedimientos viables para ello.

Por otra parte, la Convención Internacional del Niño reconoce la plena protección a los infantes, quienes gozan de todos los derechos humanos y la mayor protección por su condición.

En ese sentido -según expresa la autora Susan Turner-, resulta relevante lo resuelto por aquella Convención aludida. Lo materializa en dos factores fundamentales: Primero: Las normas que protegen la relación niño-familia; y Segundo: El interés superior del niño que debe prevalecer frente a otras normas jurídicas.

Aplicando dichos criterios al tema que nos ocupa diremos que en las legislaciones consultadas, todas ellas protegen el anonimato de los donantes. Sin embargo, atendiendo al interés superior del niño, resulta de mayor relevancia el proteger todo derecho humano a conocer cada individuo, su propio origen.

De lo asentado anteriormente, resultan claramente dos posiciones o posturas: 
1. POSICIÓN MAXIMALISTA. Que es aquella que otorga el derecho del nacido bajo esta figura de las "TRA", a conocer y reclamar la paternidad del donante, con todas las consecuencias jurídicas que implican la determinación de paternidad o maternidad.

2. POSICIÓN MINIMALISTA: Que es aquella que apoya el que se preserve el anonimato total del donante; de manera que el nacido bajo esta figura de las "TRA", no pueda acceder a ninguna información que lo lleve a tener conocimiento de quienes participaron y de su origen genético.

Los autores del libro antes mencionado, han propuesto también, entre otras cuestiones, otra tercera posición que abarca dos intermedias; las cuales se explican a continuación:

\section{POSICIONES INTERMEDIAS:}

a) Que el nacido bajo las "TRA" sólo pueda conocer datos biogenéticos del donante.

b) Que el nacido bajo las "TRA" pueda conocer la identidad personal del donante, pero sin ninguna otra consecuencia jurídica.

Lo que implicará -claro está- que el individuo nacido bajo estas condiciones tenga el derecho limitado a conocer parte de la información, con las consecuencias morales y jurídicas que se intuyen violatorias del elemental derecho de todo individuo a saber de dónde viene y hacia dónde puede seguir desarrollando libremente su personalidad en búsqueda de la propia felicidad. Circunstancia esta, bien desarrollada por el Pleno de la Suprema Corte de Justicia de la Nación Mexicana, en sendas resoluciones jurisprudenciales ya conocidas por el amable lector y que corresponden a la aplicación, entre otros del artículo $3^{\circ}$ Constitucional vigente. 


\section{Posibles implicaciones prácticas en la materia notarial}

Aunque es una realidad que no se ha llevado un caso práctico a la mesa de discusión en las altas esferas de la judicatura federal, como lo comprueba el hecho de no encontrar resoluciones relevantes de dicha alta magistratura en la materia que nos ocupa, tan bien es cierto que en la materia notarial tampoco lo hemos encontrado, por el que podamos hacer un estudio factual y concreto. Pero su novedad ya es conocida y estudiada en otros ámbitos de la academia como es el caso de Perú, en la Universidad de Lima, se abrió en el 2016, un amplio debate internacional sobre el papel que debe jugar el notario y sus implicaciones en el campo de las técnicas de reproducción asistida y del registro nacional que debe abrirse para que se hagan constar las intervenciones de los notarios en la fe pública para el caso de "Cedentes de Gametos y Embriones". Por lo que han propuesto en esas instancias el "Registro Nacional de Cedentes de Gametos y Embriones" como entidad garantista del Derecho a la Identidad que debe prevalecer en todas las naciones que contemplan esta actividad. ${ }^{6}$

Esta propuesta favorece la actividad notarial y previene el cumplimiento de aquellos factores necesarios para que se den las "TRA" garantizando -antes que a nadie- el derecho del Nacido bajo estas técnicas y bajo estas especiales circunstancias, protegiendo su derecho superior a conocer su ascendencia y las relaciones que puedan surgir para integrar una familia bajo los cánones de la moral, el derecho y las buenas costumbres enmarcadas en su localidad.

No existe un caso práctico real que podamos estudiar en nuestro país con aplicación en materia notarial, esto debido a que es un tema de tanta innovación en nuestro país, el cual aún no ha llegado a producirse, sin embargo del estudio de las demás legislaciones se deduce que tendrá gran implicación, en lo siguiente:
A) Materia sucesoria intestamentaria.
B) El otorgamiento de la voluntad a someterse a las "TRA", de acuerdo a las otras legislaciones, son otorgados ante fedatario público; consentimiento que -además-podrá ser otorgado en testamento para los

6 http://www.ulima.edu.pe/pregrado/derecho/noticias/el-derecho-notarial-del-futuro-hoy; y https://www. youtube.com/watch?v=4IjpI3LnoyU. (consultados a las 17.00 del 5 de noviembre del 2017) 
efectos de reconocimiento.

C) En materia de reconocimientos de hijos nacidos bajo estas técnicas.

D) En materia de donaciones.

F) Designación de beneficiarios.

Pero es indiscutible que la obligación de emitir el consentimiento por parte de la madre y de las parejas de hecho o de derecho de ella, antes de someterse a las "TAR", debería realizarse con la intervención del Notario Público como institución que representa la seguridad jurídica de los usuarios de sus servicios, y de la actividad previsora que para su actividad se ha señalado en la ley. Es un tema que conforme se vaya suscitando con más frecuencia en nuestro país tendrá implicaciones en distintas ramas del derecho.

\section{Conclusiones}

1.- Es innegable que el tema de la práctica de las Técnicas de Reproducción Asistida, también conocidas como "TRA", representa una tarea legislativa y reglamentaria por iniciar en nuestro país, dados los antecedente de evolución en otras legislaciones del mundo y el uso cada vez más frecuente de estas técnicas en nuestra comunidad, traídas a nosotros por compañías internacionales y como consecuencia de la necesidad de procrear que tienen ciertos sectores de nuestra población.

2.- También es cierto que ha surgido la tarea de analizar y estudiar los efectos que la práctica de las "TRA" puede traer, en la conceptualización legal de la maternidad, paternidad y filiación; por lo que en la República mexicana se debe crear - a partir de nuestra Carta Magna- una legislación especial para dichas las técnicas de reproducción asistida, en las que se contemplen la regulación eficaz de las situaciones resultantes en materia de filiación.

3.- Es un hecho palpable que la concepción del nuevo ser se produce con la unión del gameto masculino con el femenino, provocando el inicio a una nueva célula irrepetible, diferenciable de otras, y dando origen a una nueva vida biológica, 
vocacionada a convertirse en un nuevo Ser. Y es bien cierto que esto se produce dentro de un ámbito estrictamente privado de la madre portadora del producto, la cuál debe ser respetada en su integridad; ya que el feto está protegido por la norma constitucional desde que es concebido.

4.- La filiación como vínculo jurídico entre los padres e hijos que crean derechos y obligaciones debe ser ampliada a los casos de nacimiento bajo estas técnicas, protegiendo el interés superior del menor y a su derecho a mantener un conjunto de relaciones jurídico-familiares, según lo ha dejado claro Susan Turner en su obra colectiva.

5.- La filiación por las técnicas de reproducción asistida debe ser reconocida a partir del consentimiento expreso, preferiblemente emitido -en los casos previstos por la ley-mediante escritura pública y formalizadas las firmas mediante certificación que se haga ante la ineludible presencia del notario público. Todo siguiendo el principio de legalidad a que está sujeta su actividad, y a la pericia jurídica que debe guardar el notario en su actuación. Amén de las obligaciones naturales de respeto y búsqueda de fomento a los derechos humanos. Formalidad que bajo el derecho comparado, ya se advierte su utilización actualmente en Austria, como acto volitivo de los interesados y superando así, la espontánea y a veces forzada aparición del simple vínculo biológico que los impulsa a procrear.

6.- El anonimato de los donantes debe ser atendido por la legislación; sin embargo, bajo ciertas circunstancias debe privilegiarse el derecho del Nacido bajo estas técnicas de reproducción asistida, a que tenga conocimiento de su origen, pero específicamente a que se le permita conocer las características genéticas del donante.

7.- Es factible y deseable desde cualquier punto de vista, que no exista vínculo de filiación entre el donante y el nacido bajo las técnicas de reproducción asistida.

8.- Considerar en la ley agregar la filiación como consecuencia de la utilización de técnicas de reproducción asistida.

9.- La familia como base de nuestra sociedad debe ser prioritariamente protegida por nuestra legislación de manera que se contemple a la filiación como una fuente de integración de nuevas formas familiares surgidas como consecuencia del nacimiento de individuos bajo las técnicas de reproducción asistida. Constituyéndose como prioritaria su regulación, para no quedar a la zaga de los 
avances de la ciencia en esta materia.

10.- Este gran reto que deben enfrentar los legisladores constitucionales como los reglamentarios en cada una de las regiones del país, debe incorporar esfuerzos de homologación entre regiones; así como en materia de derecho procesal, a fin de establecer los procedimientos de reconocimiento, registro e impugnación de acciones y derechos en materia de filiación derivada de la utilización de las "TRA".

11.- Se integre en nuestro país una instancia de registro y control de la actividad de utilizar las "TAR", a través de un "Registro Nacional de Cedentes de Gametos y Embriones", como entidad garantista del Derecho a la Identidad ya una filiación asegurada, que debe prevalecer en todas las naciones que contemplan esta actividad, como ya lo tienen contemplado otros países de centro y Sudamérica.

\section{Bibliografía}

Reproducción Asistida ORG visitado en: 05 de Mayo de 2017 https:// www.reproduccionasistida.org/reproduccion-asistida/

Omisión e Indiferencia Derechos Reproductivos en México visitado en:

05 de Mayo de 2017 http://informe.gire.org.mx/caps/cap6.pdf

Oficio Número CAS/1/UR/2218/2012 visitado en: 05 de Mayo de 2017 https://es.scribd.com/document/123368515/cap6-1215100150212pdf

Cuestiones Constitucionales Revista Mexicana de Derecho Constitucional, visitado en: 05 de Mayo de 2017, https://revistas.juridicas.unam. mx/index.php/cuestiones-constitucionales/article/view/5790/7633

Código civil de España.

Código civil del Estado de Jalisco.

Código Civil del Estado de Tabasco.

Constitución Política de los Estados Unidos Mexicanos.

La Convención Internacional de los Derechos del Niño.

La Convención Americana sobre Derechos Humanos (Pacto de San José), (1969) 
Ley 14/2006, de 26 de mayo, sobre técnicas de reproducción humana asistida.

Ley Nacional de Fertilización Humana Asistida, identificada como: $\mathrm{N}^{\mathrm{o}}$ 26.862 .

Berlinguer, Giovanni, Bioética cotidiana, Siglo XXI Editores, S.a de C.V. México, 2002

Ciccone, Lino, Bioética, historia, principios, cuestiones, Editorial Ediciones Palabra S.A. 2 edición, Madrid, España, 2006

Díaz Martínez, Ana, La doble maternidad legal derivada de la utilización de técnicas de reproducción, Derecho Privado y Constitución ISSN: 1133-8768. Núm. 21. Enero-Diciembre 2007. Págs. 75-129

J. Bestard, G. Orobitg, J. Ribot, c. Salazar, Parentesco y Reproducción asistida: cuerpo, persona y relaciones, Universitat de Barcelona, España, 2003

Martínez Morales, Rafael, Diccionario Jurídico Contemporáneo, Iure Editores, S.A. de C.V. México, 2011

Muñoz, Benito Lucia La Filiación derivada de Técnicas de Reproducción Asistida, Universidad de La Rioja, 2016.

Petit Eugéne, "Tratado elemental de Derecho Romano", $23^{\circ}$ Edición, Ed. Porrúa, México, 2007. Pp. 95-99

Turner Saelzer, Susan, Marcia Molina Pezoa, Rodrigo Momberg Uribe, Técnicas de Reproducción Humana Asistida. Una perspectiva desde los intereses del hijo, Revista de Derecho. [volumen xi, pp. 13-26], http://mingaonline.uach.cl/pdf/revider/v11/art02.pdf.

S/A, Introducción a la Bioética, 2005 Consultado en http://www.ugr. es/ eianez/Biotecnologia/bioetica.htm, el día 03 de Septiembre de 2017.

Suprema Corte de Justicia de la Nación. tesis aislada (Constitucional) 161265; PXXII/2011 del Pleno, bajo el Tomo XXXIV. Agosto del 2011, página 879, de la Novena época con el rubro: "MATRIMONIO. LA "POTENCIALIDAD” DE LA REPRODUCCIÓN NO ES UNA FINALIDAD ESENCIAL DE AQUELLA INSTITUCIÓN”. 